\title{
Disruption and bactericidal indices depicted in polygonal graphs to show multiple outcome effects of root canal irrigant supplements on single- and dual-species biofilms
}

\author{
G. Bryce ${ }^{1}$ (D) J. Pratten ${ }^{2} \cdot$ D. Ready ${ }^{3} \cdot$ Y.-L. $\mathrm{Ng}^{4} \cdot$ K. Gulabivala ${ }^{4}$
}

Received: 17 June 2019 / Accepted: 7 January 2020 / Published online: 17 January 2020

(C) The Author(s) 2020

\begin{abstract}
Objectives The aims of this study were to (1) investigate the relative time-dependent disruption and bactericidal effects of detergent-type surfactants on single- or dual-species biofilms of root canal isolates and (2) to examine the utility of polygonal graphs for depiction of biofilm disruption and cell killing.

Materials and methods Single-species biofilms of Streptococcus sanguinis, Enterococcus faecalis, Fusobacterium nucleatum and Porphyromonas gingivalis were grown on nitro-cellulose membranes for $72 \mathrm{~h}$ and immersed in Tween ${ }^{8} 80$, cetyltrimethylammoniumbromide (CTAB), and sodium dodecyl sulphate (SDS) for 1-, 5- or 10-min ( $n=3$ per test). The number of viable and non-viable bacteria "disrupted" from the biofilm and those "remaining-attached" was determined using a viability stain in conjunction with fluorescence microscopy. The data were analysed using non-parametric Kruskal-Wallis test with 5\% significance level.

Results Gram-negative obligate anaerobes were more susceptible to cell removal than gram-positive facultative anaerobes. The majority of cells were disrupted after 1-min of exposure; however, the extent varied according to the agent and species. CTAB and SDS were more effective than Tween $80^{\mathrm{TM}}$ at disrupting biofilms and killing cells but all agents failed to achieve $100 \%$ disruption/kill.

Conclusions Biofilm disruption and cell viability were influenced by the species, the test agent and the duration of exposure. CTAB and SDS were more effective in biofilm disruption than Tween $80^{\mathrm{TM}}$. Graphical depiction of biofilm disruption- and viability-outcomes provides an alternative means of simultaneously visualising and analysing relative efficacy in different domains.

Clinical relevance Surfactants were not as effective at biofilm disruption as $\mathrm{NaOCl}$ but may be added to other non-disruptive antibacterial agents to enhance this property.
\end{abstract}

Keywords Disruption $\cdot$ Bacterial killing $\cdot$ Irrigants $\cdot$ Root canal $\cdot$ Biofilm $\cdot$ Depiction of outcome measures

Y.-L. Ng

y.ng@ucl.ac.uk

1 Defence Primary Health Care, Defence Centre for Rehabilitative Dentistry, Evelyn Woods Road, Aldershot GU11 2LS, UK

2 Public Health England, Respiratory and Systemic Bacteria Section, PHE - National Infection Service, London, UK

3 Clinical Microbiology and Public Health Laboratory, Public Health England, England, UK

4 Unit of Endodontology, Department of Restorative Dentistry, UCL Eastman Dental Institute, University College London, 256 Grays Inn Road, London WC1X 8LD, UK

\section{Introduction}

Root canal treatment (RCT) fails to predictably eradicate bacteria in the apical anatomy even after using potent antibacterial irrigants $[1,2]$. The encasement of bacteria within the root canal biofilm has been suggested as an explanation for this failure in therapy [3], emphasising the importance of biofilm disruption to facilitate subsequent and further anti-microbial action. Antibacterial agents' actions on biofilms may yield diverse outcomes that include killing, either with- or without disruption, in a time-dependent and dose-dependent manner [4]. Investigation of the disruptive and bactericidal effects of common RCT irrigants on single- and dual-species biofilms [4] found $\mathrm{NaOCl}$ to be the most effective agent at both 
bacterial killing and biofilm disruption. CHX and iodine were effective at bacterial killing but not disruption, whilst EDTA showed biofilm disruption activity but exhibited lesser antimicrobial potential [4].

In other arenas of biofilm combat, combined chemical approaches have been proposed, including, dislodgement of cells from surfaces by dispersants and weakening of the biofilm structure by enzymes [5] or chelants of divalent cations [6]. Surfactants can act as dispersants and are classified into non-ionic, cationic and anionic. Polysorbate 80 (Tween $80^{\mathrm{TM}}$ ) is a non-ionic surfactant that is added to commercially available irrigants (MTAD [3\% Doxycycline, $4.25 \%$ citric acid, $0.5 \%$ Tween $80^{\mathrm{TM}}$ ] [Dentsply Tulsa dental, Tulsa, OK]). Interestingly, the antibacterial effect of MTAD against E. faecalis biofilm was not affected by the elimination of Tween $80^{\mathrm{TM}}$ [7].

Cetyltrimethylammoniumbromide (CTAB), a cationic surfactant, is an additive in SmearClear ${ }^{\circledR}$ SybronEndo, Orange, CA, USA), Tetraclean ${ }^{\circledR}$ (1\% doxycyclin, $10 \%$ citric acid, $0.2 \%$ cetrimide; Ogna Laboratori Farmaceutici), and QMiX® (Dentsply Tulsa Dental, Tulsa, OK, USA) and has been tested in experimental irrigants (MTAC 1 and MTAC-2) [7]. CTAB may affect the biofilm by forming electrostatic bonds that weaken the extracellular matrix (ECM) [8] and has been tested against $E$. faecalis or polymicrobial root canal biofilms as a single agent [9-11] as well as in combination with other agents (EDTA, maleic and citric acids, iodine potassium iodide, CHX) with promising results [10].

Sodium dodecyl sulphate (SDS), an anionic alkyl sulphate surfactant, may act by disrupting the hydrophobic interactions involved in cross-linking ECM [12] and exhibits a cell killing effect on salivary biofilms, maintained on hydroxyapatite discs [13].

Although multiple concurrent therapy approaches may eradicate biofilm more effectively [14], the selection of appropriate adjunct agents to traditional irrigants requires an easier approach to assimilate and compare anti-biofilm information on relative biofilm killing and disruption efficacies. The killing effects of both cationic (including CTAB) [7, 9, 15] and anionic surfactants (SDS) [16] have been investigated but the disruption/dispersion function has not been simultaneously investigated.

The present study investigated the relative time-dependent disruption and bactericidal effects of detergent-type surfactants on single- and dual-species biofilms of root canal isolates and explored the utility of the disruption/killing index to depict the outcomes simultaneously, as previously proposed [4].

\section{Materials and methods}

The bacterial isolates, from infected root canal systems, used in the study were Streptococcus sanguinis (Ss) E01-07-001,
Enterococcus faecalis (Ef) E01-07-048, Porphyromonas gingivalis $(P g)$ E01-07-035 and Fusobacterium nucleatum $(F n)$ E01-07-13. The isolates had been identified using partial 16S rRNA gene homology supplemented by biochemical analysis (API Strep32 system, Biomerieux, Basingstoke, UK), with purity assessed by Gram staining and microscopic examination.

The test solutions selected were Tween $80^{\mathrm{TM}}\left(\right.$ Sigma ${ }^{\circledR}$, Sigma Aldrich, St Louis, MO, USA), CTAB (10 mg/mL CTAB, Sigma $\left.{ }^{\circledR}\right)$ and SDS $\left(0.05 \mathrm{mg} / 100 \mathrm{~mL}\right.$ SDS, Sigma $\left.{ }^{\circledR}\right)$. Reduced transport fluid (RTF) [17] was used as a negative control. $\mathrm{NaOCl}(1 \%)$, iodometrically titrated (5\% Teepol Bleach ${ }^{\circledR}$, Teepol Products, Egham, UK) was used as a positive control.

Single-species biofilms were generated on nitro-cellulose membranes following a previously described protocol [18]. Briefly, $20 \mu \mathrm{L}$ aliquots of a standardized culture (absorbance of 0.4 at $540 \mathrm{~nm}$ for all species) were inoculated onto sterile membrane filters $(0.2 \mu \mathrm{m}$ pore size, $5 \mathrm{~mm}$ diameter; Whatman International Ltd., Maidstone, UK) and placed on Blood Agar plates (BA; Oxoid, Basingstoke, UK). S. sanguinis and E. faecalis were incubated at $37{ }^{\circ} \mathrm{C}$ in air supplemented with $5 \% \mathrm{CO}_{2}$ for $48 \mathrm{~h}$, while $P$. gingivalis and $F$. nucleatum were incubated in an anaerobic cabinet (Don Whitley Scientific Ltd., Shipley, UK) at $37^{\circ} \mathrm{C}$ for $72 \mathrm{~h}$. Dual-species biofilms were generated using two of the test species (S. sanguinis and F. nucleatum). The ratio of the organisms was 1:2 (absorbance of 0.2 and 0.4 at $540 \mathrm{~nm}$ ) for the $S$. sanguinis and $F$. nucleatum, respectively, and these were incubated anaerobically at $37^{\circ} \mathrm{C}$ for $72 \mathrm{~h}$.

Single- ( $n=15$ per agent) and dual-species $(n=15$ per agent) biofilms were cultured and exposed to $1 \mathrm{~mL}$ of either the test agent or the control (RTF) within a validated disruptive assay protocol [19] at room temperature under aerobic conditions for 1-, 5- or 10-min, as previously described [4]. After the designated contact time, each membrane filter was removed and placed into $1 \mathrm{~mL}$ of neutralizing broth (NB; BD Difco, Oxford, UK). To determine the number of cells "disrupted" from the biofilm, the filter was vortexed at $200 \mathrm{rpm}$ for $20 \mathrm{~s}$ to re-suspend the cells sufficiently loosened by the effect of the test agent from the biofilm. Each membrane filter was then transferred to a sterile $3-\mathrm{mL}$ bottle containing $1 \mathrm{~mL}$ of RTF and vortexed at full speed for $1 \mathrm{~min}$ to remove the greater majority of bacteria "remaining-attached" to the membrane.

Five-point cell counts (live and dead cells) were conducted [20] using a microscope with a fluorescent light source (Olympus, Watford, UK) and viability stain (LIVE/DEAD® BacLight ${ }^{\mathrm{TM}}$, Invitrogen, Paisley, UK) to produce mean cell counts of both the "disrupted" and "remaining attached" cells. The control specimens ( $n=3$ per species) were only briefly exposed to RTF to enumerate base-line cell counts . 
Each experiment was carried out in triplicate ( 3 technical and 5 biological repeats yielding 15 data sets per test agent/ species), and the number of remaining-attached cells (live or dead) harvested from the single- or dual-species biofilms exposed to various test agents was compared with those exposed to RTF using the non-parametric Kruskal-Wallis test (STATA version 9.2, STATA Corporation, College Station, TX, USA). The significance level was set at $5 \%$.

Four-axes polygraphs were used to present the proportions of "disrupted" and "remaining-attached" live/dead cells (Fig. 1a). A measure of cells lost by complete disintegration in the test solutions is inferred from the area under the plot (the smaller the area, the greater the disintegration, as represented by the data for SDS and CTAB), since this is not a real number. In an alternative approach to account numerically for cells lost by disintegration in the test/control agent, a five-axes disruption/killing polygraph (Fig. 1b) was derived. In this approach, the baseline count was used as the denominator to calculate the proportion of live/dead cells amongst the disrupted and remaining-attached cells harvested; the fifth axis/point was annotated "lost cells", the quantity of which was estimated as the difference between the baseline count and the total number of "disrupted" and "remaining-attached" cells harvested. Figure 1b shows a large proportion of "lost cells" after exposure to SDS or CTAB, which is consistent with the small plot area displayed in Fig. 1a.

In addition to the quantitative analyses, qualitative Confocal laser scanning microscopy (CLSM) was also carried out using a Bio-Rad MRC 2000® (Hemel Hempstead, UK). Briefly, membrane filters containing biofilms were attached to the base of a $5-\mathrm{cm}$ sterilin dish using a small drop of glue (Loctite ${ }^{\circledR}$, Winsford, Cheshire, UK). The filters were then covered with $5 \mathrm{~mL}$ of BacLight ${ }^{\mathrm{TM}}$ viability stain and left to incubate for $10 \mathrm{~min}$ and viewed with a water immersion
Fig. 1 Disruption index polygraphs with a four- or $\mathbf{b}$ fiveaxes (a)

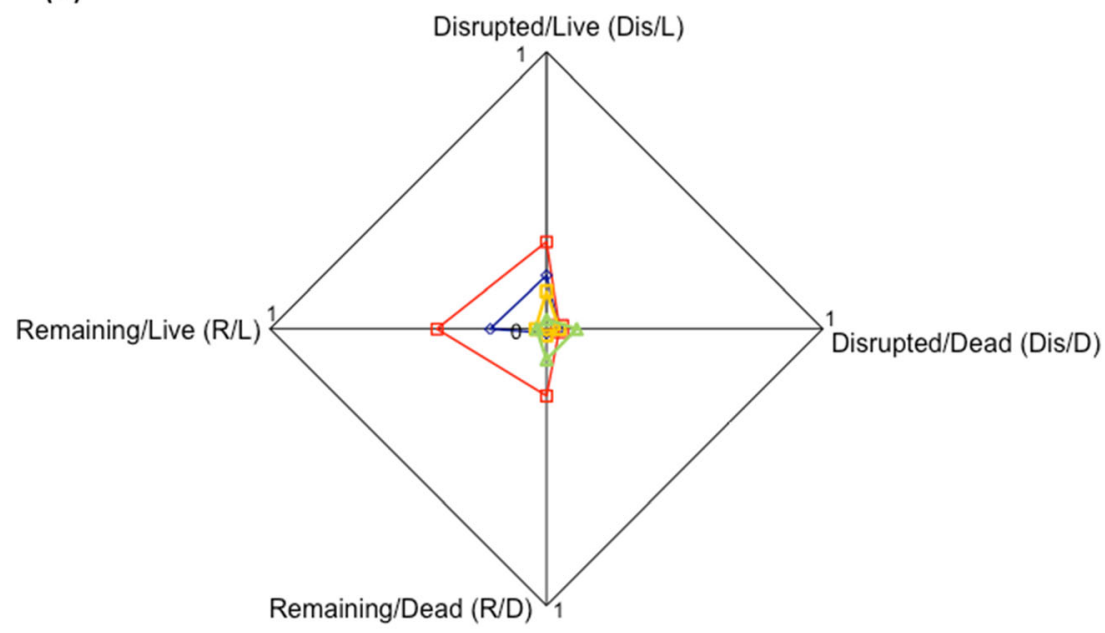

(b)

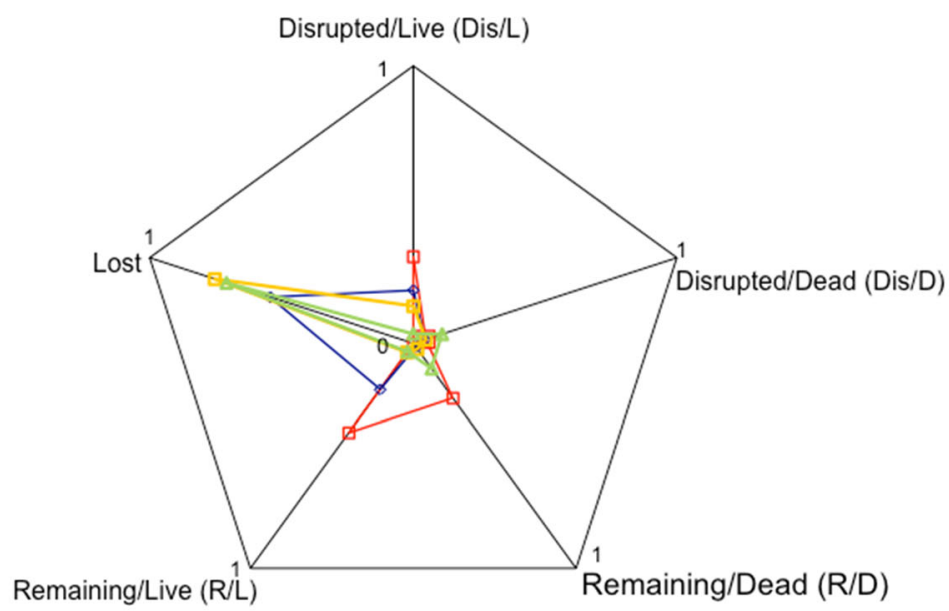

$\Rightarrow 10 \mathrm{~min}$ RTF $\rightarrow 10 \mathrm{~min}$ Tween $80 \rightarrow-10 \mathrm{~min}$ SDS $\rightarrow 10 \mathrm{~min}$ CTAB 
objective (Olympus $\left.{ }^{\circledR} \times 40\right)$. These images were then constructed and manipulated using a software programme (Image J®, http://rsb.info.nih.gov/ij/).

\section{Results}

\section{Single-species biofilms}

The mean number (and standard deviations) of "remainingattached live" (R/L)-, "remaining attached dead" (R/D)-, "disrupted live" (Dis/L)- or "disrupted dead" (Dis/D)- cells per slide view (5 fields) from single species biofilms $(n=3)$ at baseline and following exposure to test- or control-agents are presented in Table 1. The base-line data demonstrated the validity of the definition of "disrupted" versus "remainingattached", in that without immersion for the designated time in a test or control agent, none of the species showed removal of either live or dead cells. Even at baseline, there were relatively high proportions of R/D cells in the $F n$ and $P g$ groups.

All agents, including RTF, disrupted the single-species biofilms. After RTF exposure, the "disrupted" and "remaining-attached" S.s cells were all live, whilst $E f, F n$ and $P g$ biofilms contained a population of both live (larger fraction) and dead (smaller fraction) cells. There were also reduced numbers of "remaining-attached" cells recovered from $P g$ biofilms after 5- or 10-min exposure to RTF, when compared with 1-min exposure or the baseline. After $\mathrm{NaOCl}$ exposure, minimal dead cells (disrupted and "remaining-attached") could be harvested, after 5- or 10-min exposure.

Table 2 shows that the number of $\mathrm{R} / \mathrm{L}$ and $\mathrm{R} / \mathrm{D}$ cells harvested from the single-species biofilms exposed to test agents were lower than the number of cells harvested after exposure to RTF, with exceptions of $S s$ biofilms exposed to Tween $80^{\mathrm{TM}}$ and $P g$ biofilms exposed to CTAB.

There was no significant difference in Ss biofilm disruption by the different test agents compared with RTF, regardless of duration of exposure (Table 2). However, after 10-min exposure to Tween $80^{\mathrm{TM}}$ or CTAB, a large proportion of "remaining-attached" cells harvested were dead (Table 1).

Exposure of $E f$ biofilms to the test agents for 1- or 5-min (except for 1-min exposure to Tween $80^{\mathrm{TM}}$ ) resulted in fewer "remaining-attached" cells harvested when compared with RTF (Table 1). Exposure of $E f$ biofilms to Tween $80^{\mathrm{TM}}$ or CTAB for 10 min resulted in a small fraction of recovered $\mathrm{R} / \mathrm{D}$ cells (Table 1 ). Tween $80^{\mathrm{TM}}$, over time, resulted in increased "lost" $E f$ cells but stable proportions of $\mathrm{R} / \mathrm{L}$ cells. A large proportion of cells were "lost" after exposure to SDS or $\mathrm{CTAB}$ with the former being slightly more effective in disruption and killing.

There were no $\mathrm{R} / \mathrm{L}$ or $\mathrm{D} / \mathrm{L}$ cells recovered after 10 -min exposure (Table 1) from the $F n$ and $P g$ biofilms. After 5- or 10-min exposures of $F n$ biofilms to various agents, the number of "remaining-attached" cells was significantly $(p<0.01)$ less than with RTF (Table 2), although this was not replicated within the $P g$ group.

\section{Dual-species biofilm}

In the dual-species tests (Table 3), substantially more $S s$ cells were recovered compared to $F n$ cells. The majority of $S s$ cells remained attached to the membrane, whereas smaller proportions of $F n$ cells remained attached after exposure to RTF when compared with the baseline count (Table 3). In general, SDS was the most effective agent at disrupting both $S s$ and $F n$ contents of the dual species biofilm; it was followed by CTAB and then Tween $80^{\mathrm{TM}}$. The number of "remaining-attached" $S s$ or $F n$ cells exposed to SDS was significantly $(p<0.05)$ less than those exposed to RTF (Table 3). After exposure to CTAB, the $S s$ "remaining-attached" cells were significantly $(p=0.02)$ less than those exposed to RTF but this was not observed amongst the $F n$ cells.

A graphical approach to improve visualisation of the complex data depicts the data sets in two polygonal graph formats (4-axes and 5-axes) to compare the outcomes for the test/ control agents (Fig. 2).

\section{Discussion}

The three selected test agents represented each of the three types of surfactants and had reported biofilm disruptive capability $[4,11,21]$. RTF was employed as a negative control as it was expected to exert a minimal effect on the biofilm because of its transport medium role. The control confirmed that the disruption protocol incurred cell death and was therefore used to gauge the relative rate of cell death across the test agents. Positive control data using $\mathrm{NaOCl}$ and test model parameters were published previously [4]; the model allowed evaluation of the relative bactericidal and biofilm disruption effects of the test agents.

Root canal irrigants have been tested in vitro using a variety of biofilm models [7, 22-24], with perceived advantages and disadvantages attributed to each. Generation of biofilms on dentine discs, or in root canals, may have greater proximity to the clinical scenario but carry other confounding risks, including variable dentinal tubule structure, root canal geometry, buffering effect, residual pulp- or organic tissue, inclusion of stagnation planes and vapour lock effects $[25,26]$. The well-established nitrocellulose disc model was therefore chosen as the substrate for the present study to exclude such confounding effects. Multi-species biofilms grown for at least 3 weeks show increased maturity and survival, when exposed to anti-microbial agents, compared to those grown with more limited durations [27]. The mono-and dual-species biofilms 


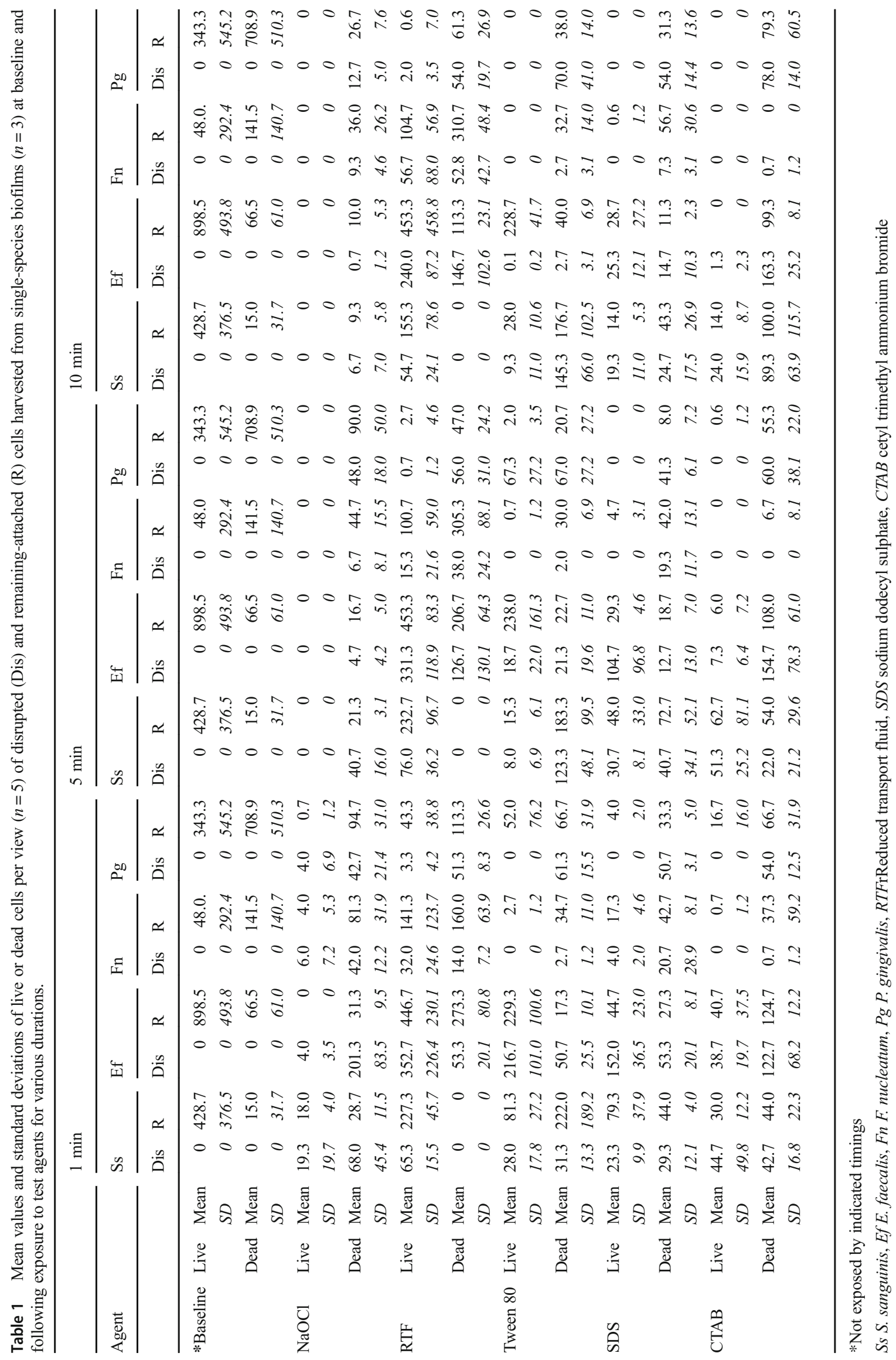


Table 2 Comparisons of "remaining-attached" cells of $S$. sanguinis, $E$. faecalis, $F$. nucleatum and $P$. gingivalis after exposure to test agents or RTF for various durations

\begin{tabular}{|c|c|c|c|}
\hline & $1 \mathrm{~min}$ & $5 \mathrm{~min}$ & $10 \mathrm{~min}$ \\
\hline \multicolumn{4}{|l|}{ S. sanguinis } \\
\hline$* R T F$ & $227.3 \pm 26.4$ & $232.7 \pm 55.8$ & $155.3 \pm 45.4$ \\
\hline RTF-Tween 80 & $-76.0 \pm 116.7$ & $34.0 \pm 82.6$ & $-49.3 \pm 75.6$ \\
\hline RTF-SDS & $104.0 \pm 35.7$ & $112.0 \pm 61.0$ & $98.0 \pm 47.3$ \\
\hline RTF-CTAB & $153.3 \pm 32.3$ & $116.0 \pm 78.4$ & $41.3 \pm 79.9$ \\
\hline \multicolumn{4}{|l|}{ E. faecalis } \\
\hline$* R T F$ & $720.0 \pm 179.3$ & $660.0 \pm 20.0$ & $566.7 \pm 257.3$ \\
\hline RTF-Tween 80 & $473.3 \pm 186.8$ & $399.3 \pm 95.5^{* *}$ & $298.0 \pm 258.8$ \\
\hline RTF-SDS & $648.0 \pm 180.2 * *$ & $612.0 \pm 20.1 * *$ & $526.7 \pm 257.7$ \\
\hline RTF-CTAB & $554.7 \pm 181.5^{* *}$ & $546.0 \pm 41.2^{* *}$ & $467.3 \pm 257.3$ \\
\hline \multicolumn{4}{|l|}{ F. nucleatum } \\
\hline$* R T F$ & $301.3 \pm 99.7$ & $406.0 \pm 83.1$ & $415.3 \pm 40.7$ \\
\hline RTF-Tween 80 & $264.0 \pm 99.9$ & $375.3 \pm 83.2 * *$ & $382.7 \pm 41.5 * *$ \\
\hline RTF-SDS & $241.3 \pm 99.9$ & $359.3 \pm 83.3 * *$ & $358.0 \pm 44.2 * *$ \\
\hline RTF-CTAB & $263.3 \pm 105.6$ & $399.3 \pm 83.2 * *$ & $415.3 \pm 40.7$ *** \\
\hline \multicolumn{4}{|l|}{ P. gingivalis } \\
\hline$* R T F$ & $156.7 \pm 37.7$ & $50.0 \pm 15.0$ & $68.0 \pm 19.4$ \\
\hline RTF-Tween 80 & $38.0 \pm 68.1$ & $27.3 \pm 23.2$ & $30.0 \pm 21.0$ \\
\hline RTF-SDS & $119.3 \pm 37.9$ & $42.0 \pm 15.6$ & $36.7 \pm 21.0$ \\
\hline RTF-CTAB & $73.3 \pm 39.8$ & $-6.0 \pm 19.9$ & $-11.3 \pm 40.0$ \\
\hline
\end{tabular}

*The mean ( \pm standard error) of attached cells recovered following exposure to RTF

**The difference between RTF and test agent was significant at the $1 \%$ level

were tested at 48 and $72 \mathrm{~h}$ in the present study and so may yield comparatively different cellular-killing rates.

Although the biofilms were grown anaerobically, the disruption assays could practically only be performed under normal atmospheric conditions and may have negatively affected the biofilms, explaining the substantial killing and disruption efficacy of the RTF on $P g$. However, clinical treatment also incurs aerobiosis and so arguably the test provides realism in that sense [22].

The Gram-negative anaerobic biofilms were more susceptible to the test surfactants than their Gram-positive facultative counterparts, an observation consistent with previous disruption assays [4] and in vivo findings [28]. The similarity between the disruption and killing of $S s$ and $F n$ grown in singleversus dual-species biofilms was in keeping with a study that found no difference in CHX efficacy against $S s$ grown as single-species biofilms and within plaque microcosms [29]. In contrast, other species became more resistant to hydrogen peroxide and tetracycline when grown within multispecies biofilms [30], with the inference that enhanced resistance resulted from increased biofilm depth and, as yet to be substantiated factors such as, quorum sensing [30].
Table 3 Mean values and standard deviations of live or dead cells per view $(n=5)$ of disrupted (Dis) or "remaining-attached" (R) cells harvested from dual species biofilms $(n=3)$ at baseline and following exposure to test agents for $1 \mathrm{~min}$. Ss $S$. sanguinis, Fn F. nucleatum

\begin{tabular}{|c|c|c|c|c|c|c|}
\hline \multirow[t]{2}{*}{ Agent } & & & \multicolumn{2}{|l|}{ Ss } & \multicolumn{2}{|l|}{ Fn } \\
\hline & & & Dis & $R$ & Dis & $R$ \\
\hline \multirow[t]{4}{*}{ *Baseline } & Live & Mean & 0 & 784.7 & 0 & 360.0 \\
\hline & & $S D$ & 0 & 830.6 & 0 & 163.9 \\
\hline & Dead & Mean & 0 & 200.0 & 0 & 60.0 \\
\hline & & $S D$ & 0 & 185.2 & 0 & 63.2 \\
\hline \multirow[t]{4}{*}{$\mathrm{NaOCl}$} & Live & Mean & 3.3 & 9.3 & 0.7 & 0 \\
\hline & & $S D$ & 7.2 & 16.7 & 2.6 & 0 \\
\hline & Dead & Mean & 70.7 & 28.7 & 14.0 & 0 \\
\hline & & $S D$ & 111.0 & 26.4 & 14.5 & 16.8 \\
\hline \multirow[t]{4}{*}{ RTF } & Live & Mean & 54.0 & 630.7 & 0 & 8.7 \\
\hline & & $S D$ & 120.1 & 625.5 & 0 & 20.0 \\
\hline & Dead & Mean & 29.3 & 37.3 & 36.0 & 12.0 \\
\hline & & $S D$ & 30.1 & 35.8 & 59.6 & 18.2 \\
\hline \multirow[t]{5}{*}{ Tween 80} & Live & Mean & 6.0 & 118.0 & 0 & 4.0 \\
\hline & & $S D$ & 18.4 & 142.8 & 0 & 7.4 \\
\hline & Dead & Mean & 39.3 & 187.3 & 2.7 & 9.3 \\
\hline & & $S D$ & 52.6 & 239.9 & 8.0 & 12.8 \\
\hline & & & & $* * p=0.1$ & & $* * p=0.8$ \\
\hline \multirow[t]{5}{*}{ SDS } & Live & Mean & 34.7 & 43.3 & 0 & 0 \\
\hline & & $S D$ & 55.1 & 72.8 & 0 & 0 \\
\hline & Dead & Mean & 21.3 & 46.0 & 0 & 0 \\
\hline & & $S D$ & 24.5 & 54.0 & 0 & 0 \\
\hline & & & & $* * p=0.001$ & & $* * p=0.003$ \\
\hline \multirow[t]{5}{*}{ CTAB } & Live & Mean & 30.7 & 98.7 & 0 & 2.0 \\
\hline & & $S D$ & 40.3 & 268.5 & 0 & 4.1 \\
\hline & Dead & Mean & 242.7 & 218.7 & 24.0 & 26.0 \\
\hline & & $S D$ & 725.5 & 434.2 & 63.8 & 63.8 \\
\hline & & & & $* * p=0.02$ & & $* * p=0.7$ \\
\hline
\end{tabular}

** $p$ values for Kruskal-Wallis test comparing the total number of remaining-attached (live or dead) cells exposed to the test agent against those exposed to RTF

CTAB disruptive efficacy against $E f$ biofilm was consistent with other studies [9]. SDS showed similar disruptive capabilities against all tested biofilms and was not less effective at eliminating Gram-negative species than its cationic counterparts, as previously reported [31].

The inherent positive or negative charges in CTAB and SDS may explain their more pronounced biofilm disruption and killing properties than the non-ionic surfactant, Tween $80^{\mathrm{TM}}$. CTAB is rapidly adsorbed to bacterial cell surfaces due to its positive charge, causing cell membrane disorganisation and potentially rendering the bacteria more negatively charged and hydrophobic [32].

The proposed 4-axes disruption polygraph [4] was modified to depict and facilitate comparison of the relative killing 

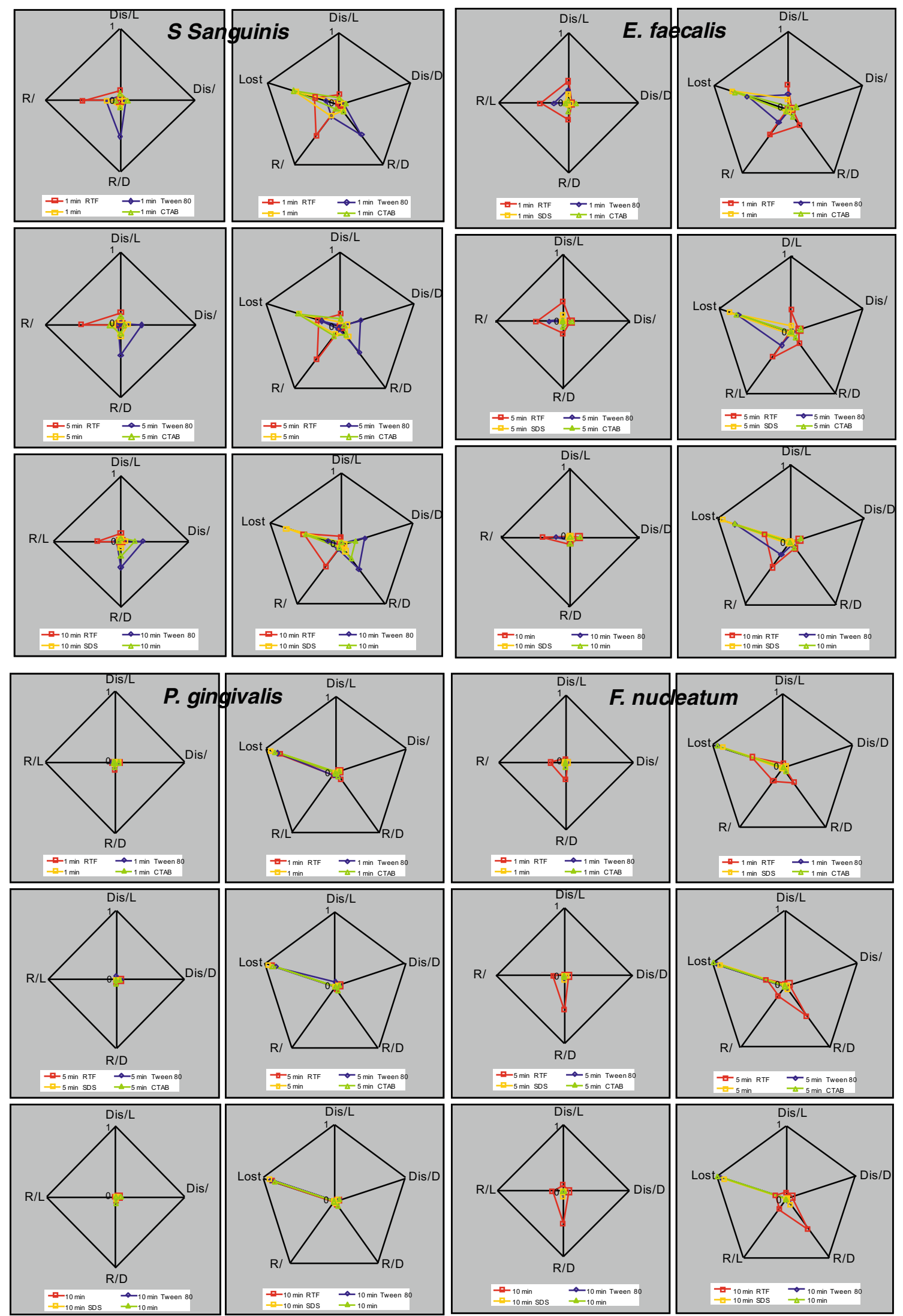

Fig. 2 Four-axes (left columns) and five-axes (right columns) disruption/bactericidal indices depicting the relative proportion of biofilm disruption and bacterial killing by test agents and test species. (Dis, disrupted; R, remaining; L, live; D, dead) 
Fig. 3 Confocal micrographs of a $S$. sanguinis $(300 \times 300 \mu \mathrm{m}), \mathbf{b}$

E. faecalis $(400 \times 100 \mu \mathrm{m})$ and $\mathbf{c}$ $S$. sanguinis and $F$. nucleatum dual species $(400 \times 100 \mu \mathrm{m})$. (i) control biofilm and (ii) after 1min immersion in $\mathrm{CTAB}$
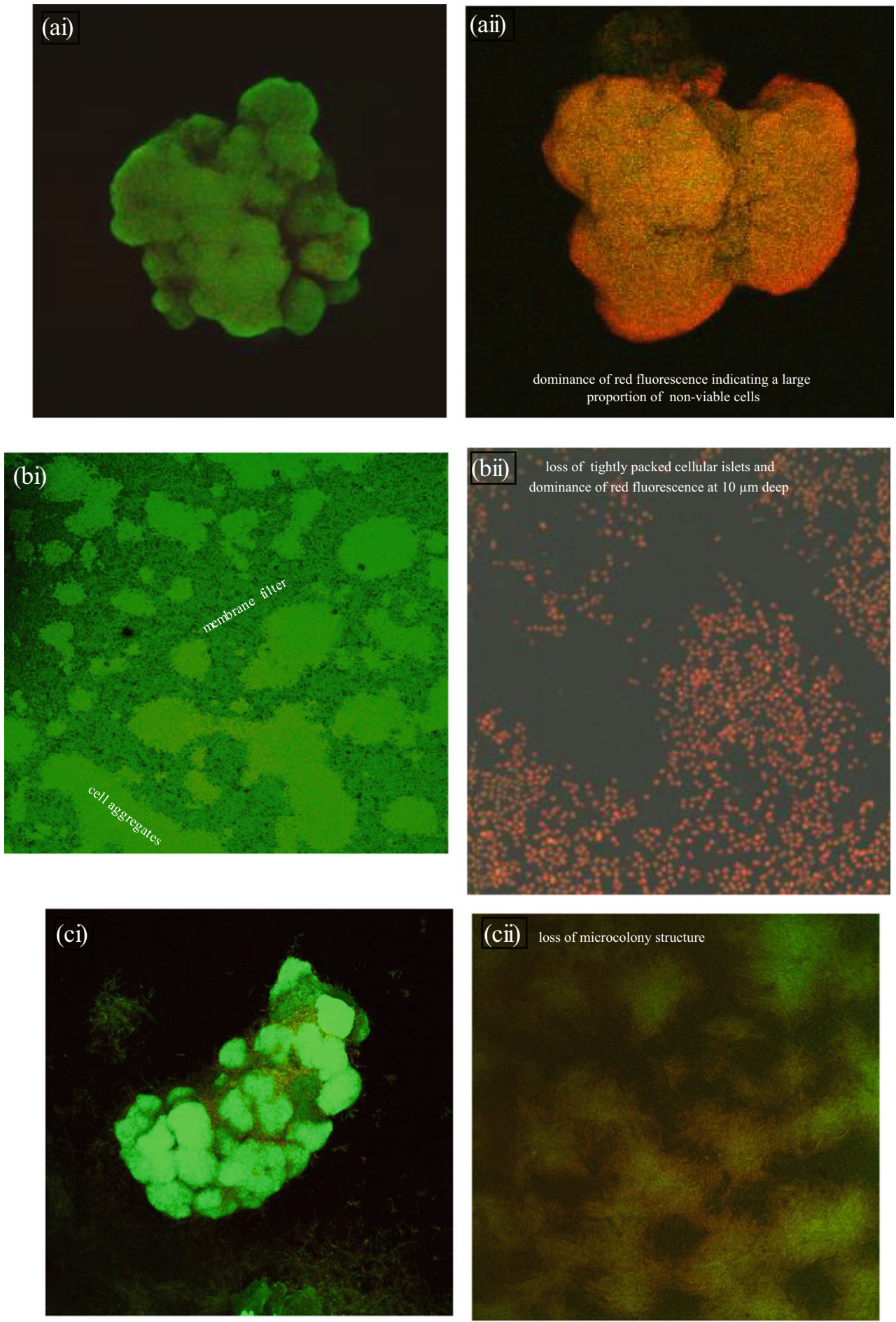

and disruption effects of the test agents against the singlespecies biofilms (Fig. 2). A shortcoming of the 4-axes polygraph is that it does not provide a direct measure of the disintegrated cells but depicts inferred "loss" of cells by virtue of fewer quantifiable cells giving a smaller area under the plot.

In the alternative approach, the disintegrated biofilm component is estimated from the discrepancy between number of cells at baseline compared with those recovered after test agent exposure, presented as the fifth axis (Fig. 2).

Confocal laser scanning microscopy (CLSM; Bio-Rad MRC 2000®, Hemel Hempstead, UK) was used to characterise the disruptive effect of CTAB, using a previously reported method [4]. Although the structural integrity of the $S s$ biofilm appeared relatively intact, the dominating red fluorescence 
indicated a large proportion of dead cells. In contrast, the $E f$ biofilm showed only a single layer of dead cells. The absence of cellular structures in the $F n$ and $P g$ biofilms (Fig. 3) was in keeping with the disruption assay results.

Synergism or potentiation of antimicrobial effect by combining agents is a valid tactic $[9,10,14]$ and the use of an ionic surfactant, such as SDS or CTAB, either as a mixture or an additional step when using non-disruptive conventional irrigants and may be considered in future research and clinical practice. The multiple outcome measure depiction in polygraphs offers a simple, visual comparison to assess antagonism, synergism or potentiation.

\section{Conclusions}

The multiple outcome measures of antimicrobial effect on biofilms, depicted in the 4- or 5-axes polygonal graphs, facilitate an alternative means of visualizing complex data for comparison of selected variables. Biofilm disruption and cell viability were influenced by species, test agents and duration of exposure. SDS and CTAB generally showed good cell disruption and killing properties but failed to achieve $100 \%$ effect.

\section{Compliance with ethical standards}

Conflict of interests The authors declare that they have no conflict of interest.

Open Access This article is licensed under a Creative Commons Attribution 4.0 International License, which permits use, sharing, adaptation, distribution and reproduction in any medium or format, as long as you give appropriate credit to the original author(s) and the source, provide a link to the Creative Commons licence, and indicate if changes were made. The images or other third party material in this article are included in the article's Creative Commons licence, unless indicated otherwise in a credit line to the material. If material is not included in the article's Creative Commons licence and your intended use is not permitted by statutory regulation or exceeds the permitted use, you will need to obtain permission directly from the copyright holder. To view a copy of this licence, visit http://creativecommons.org/licenses/by/4.0/.

\section{References}

1. Byström A, Sunvqvist G (1985) The antibacterial action of sodium hypochlorite and EDTA in 60 cases of endodontic therapy. Int Endod J 18(1):35-40

2. Nair P, Henry S, Cano V, Vera J (2005) Microbial status of apical root canal system of human mandibular first molars with primary apical periodontitis after "one-visit" endodontic treatment. Oral Surg Oral Med Oral Pathol Oral Radiol Endod 99(2):231-252

3. de Paz LC (2007) Redefining the persistent infection in root canals: possible role of biofilm communities. J Endod 33(6):652-662

4. Bryce G, O'Donnell D, Ready D, Y-1 N, Pratten J, Gulabivala K (2009) Contemporary root canal irrigants are able to disrupt and eradicate single-and dual-species biofilms. J Endod 35(9):12431248

5. Lu TK, Collins JJ (2007) Dispersing biofilms with engineered enzymatic bacteriophage. Proc Natl Acad Sci 104(27):11197-11202

6. Chen X, Stewart P (2002) Role of electrostatic interactions in cohesion of bacterial biofilms. Appl Microbiol Biotechnol 59(6):718 720

7. Pappen F, Shen Y, Qian W, Leonardo M, Giardino L, Haapasalo M (2010) In vitro antibacterial action of Tetraclean, MTAD and five experimental irrigation solutions. Int Endod J 43(6):528-535

8. Cloete TE, Jacobs L, Brözel VS (1998) The chemical control of biofouling in industrial water systems. Biodegradation 9(1):23-37

9. Arias-Moliz MT, Ferrer-Luque CM, González-Rodríguez MP, Valderrama MJ, Baca P (2010) Eradication of Enterococcus faecalis biofilms by cetrimide and chlorhexidine. J Endod 36(1): 87-90

10. Wang Z, Shen Y, Ma J, Haapasalo M (2012) The effect of detergents on the antibacterial activity of disinfecting solutions in dentin. J Endod 38(7):948-953

11. Guerreiro-Tanomaru J, Nascimento C, Faria-Júnior N, Graeff M, Watanabe E, Tanomaru-Filho M (2014) Antibiofilm activity of irrigating solutions associated with cetrimide. Confocal laser scanning microscopy. Int Endod J 47(11):1058-1063

12. Chen X, Stewart PS (2000) Biofilm removal caused by chemical treatments. Water Res 34(17):4229-4233

13. Gawande P, LoVetri K, Yakandawala N, Romeo T, Zhanel G, Cvitkovitch D, Madhyastha S (2008) Antibiofilm activity of sodium bicarbonate, sodium metaperiodate and SDS combination against dental unit waterline-associated bacteria and yeast. J Appl Microbiol 105(4):986-992

14. Wolcott RD, Gontcharova V, Sun Y, Dowd SE (2009) Evaluation of the bacterial diversity among and within individual venous leg ulcers using bacterial tag-encoded FLX and titanium amplicon pyrosequencing and metagenomic approaches. BMC Microbiol 9(1): 226

15. Ferrer-Luque CM, Arias-Moliz MT, González-Rodríguez MP, Baca P (2010) Antimicrobial activity of maleic acid and combinations of cetrimide with chelating agents against Enterococcus faecalis biofilm. J Endod 36(10):1673-1675

16. Lima KC, Fava LR, Siqueira JF (2001) Susceptibilities of Enterococcus faecalis biofilms to some antimicrobial medications. J Endod 27(10):616-619

17. Syed SA, Loesche WJ (1972) Survival of human dental plaque flora in various transport media. Appl Microbiol 24(4):638-644

18. Spratt D, Pratten J, Wilson M, Gulabivala K (2001) An in vitro evaluation of the antimicrobial efficacy of irrigants on biofilms of root canal isolates. Int Endod J 34:300-307

19. Petraki S (2011) The disruption effect of DNase I on single-species E. faecalis biofilms. MSc, University College London

20. Defives C, Guyard S, Oularé M, Mary P, Hornez J (1999) Total counts, culturable and viable, and non-culturable microflora of a French mineral water: a case study. J Appl Microbiol 86(6):10331038

21. Dunavant TR, Regan JD, Glickman GN, Solomon ES, Honeyman AL (2006) Comparative evaluation of endodontic irrigants against Enterococcus faecalis biofilms. J Endod 32(6):527-531

22. Huth K, Quirling M, Maier S, Kamereck K, Alkhayer M, Paschos E, Welsch U, Miethke T, Brand K, Hickel R (2009) Effectiveness of ozone against endodontopathogenic microorganisms in a root canal biofilm model. Int Endod J 42(1):3-13

23. Bhuva B, Patel S, Wilson R, Niazi S, Beighton D, Mannocci F (2010) The effectiveness of passive ultrasonic irrigation on intraradicular Enterococcus faecalis biofilms in extracted singlerooted human teeth. Int Endod J 43(3):241-250

24. Sena N, Gomes B, Vianna M, Berber V, Zaia A, Ferraz C, SouzaFilho F (2006) In vitro antimicrobial activity of sodium 
hypochlorite and chlorhexidine against selected single-species biofilms. Int Endod J 39(11):878-885

25. Gulabivala K (2004) Species richness of gram-positive coccoid morphotypes isolated from untreated and treated root canals of teeth Associated with periapical disease [PhD Thesis]. University of London

26. Gulabivala K, Ng Y, Gilbertson M, Eames I (2010) The fluid mechanics of root canal irrigation. Physiol Meas 31(12):R49-R84

27. Stojicic S, Shen Y, Haapasalo M (2013) Effect of the source of biofilm bacteria, level of biofilm maturation, and type of disinfecting agent on the susceptibility of biofilm bacteria to antibacterial agents. J Endod 39(4):473-477

28. Möller ÅJ, Fabricius L, Dahlén G, Sundqvist G, Happonen RP (2004) Apical periodontitis development and bacterial response to endodontic treatment. Experimental root canal infections in monkeys with selected bacterial strains. Eur J Oral Sci 112(3):207-215
29. Pratten J, Smith A, Wilson M (1998) Response of single species biofilms and microcosm dental plaques to pulsing with chlorhexidine. J Antimicrob Chemother 42(4):453-459

30. Burmølle M, Webb JS, Rao D, Hansen LH, Sørensen SJ, Kjelleberg S (2006) Enhanced biofilm formation and increased resistance to antimicrobial agents and bacterial invasion are caused by synergistic interactions in multispecies biofilms. Appl Environ Microbiol 72(6):3916-3923

31. Rajagopal S, Eis N, Nickerson KW (2003) Eight Gram-negative bacteria are 10000 times more sensitive to cationic detergents than to anionic detergents. Can J Microbiol 49(12):775-779

32. McDonnell G, Russell AD (1999) Antiseptics and disinfectants: activity, action, and resistance. Clin Microbiol Rev 12(1):147-179

Publisher's note Springer Nature remains neutral with regard to jurisdictional claims in published maps and institutional affiliations. 